\title{
Ensayo
}

\section{Universidad y cultura}

Alvaro Mauricio Flórez Escobar

Docente Facultad de Odontología.

\begin{abstract}
«!Qué alegre parece el Maestro!» observó un visitante.
\end{abstract}

«Uno siempre camina con paso alegre cuando se ha librado de esa carga que llamamos 'ego'», dijo un discípulo.

\author{
Anthony de Melo
}

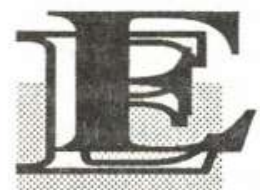

$S$ indudable el papel que desempeña la Universidad en la sociedad. La influencia que ejerce sobre todas las esferas sociales se dirige hacia aquellas metas que se proponen ántora alcanzables en la práctica por el ejercicio cotidiano y tesonero de sus funciones y quehaceres. Los protagonistas se convierten en forjadores de ideales que están íntimamente relacionados con la evolución del hombre y la ciencia.

La Universidad poseé marcas únicas, la originalidad abarca características inseparables, que a la vez son su manifestación externa. Son aquellas donde la Universidad es ciencia, donde el quehacer universitario es cooperativo de maestros y donde la nota universal comprende la apertura con el fin de ampliar todas las perspectivas de conocimiento y cultura.

La formación del hombre se convierte en su esencia. La investigación, la difusión de la ciencia, el hacer y servir a la sociedad se transforma en el ejercicio de sus funciones. Por ello, el compromiso con las metas o fines dan fundamento a su nota más profunda y sustancial : la Autonomía.

La autonomía se sustenta sobre el poder del saber y es la libertad de acción responsable de la Universidad para «hacer ciencia» y para autoadministrarse. Los ejercicios libres que enmarcan la autonomía se rectifican en la decisión sobre la selección, incorporación y régimen de estudiantes. Laselección de los recursos humanos, académicos y administrativos; el escoger y 
estructurar los programas académicos y metodologías pedagógicas. Determinar la naturaleza y métodos de programas investigativos y, ejercer las funciones de autogestión financiera. Por ello no nos equivocaríamos al decir que la Universidad y su autonomía en lo mas profundo de su ser, se alimenta por la libertad del espíritu pensante. Si ello es así, participa Ud. en el cumplimiento de las funciones de la Universidad? Realmente Ud. está comprometido con la misión de la Universidad?

Cada uno de nosotros hace parte de la dinámica en la enseñanza y la docencia universitaria. Se pretende en un mañana, ser educadores en lo superior y para lo superior. Pero, verdaderamente que es lo distingue a un buen maestro?

El siguiente ejemplo permite establecer algunas características particulares que se deben conservar como una reflexión de ideas y principios para involucrar nuestra naturaleza y vocación docente a la cultura universitaria .

Generalmente, lo que distingue al maestro es el saber llegar a los valores del pensamiento de la vida, así se enseñe matemáticas o biología. El maestro no es jefe que comanda, no exige obediencia ciega, crea independencia en el alumno. Nada exige del alumno que antes no se haya exigido a sí mismo, mantiene las puertas del diálogo y la discusión crítica. Sugiere, insinua, advierte, enseña, induce y propicia el saber del alumno. Nunca busca convertir a sus alumnos en condicionados creyentes. Conoce las medidas de la sencillez y humildad, nunca todo ni siquiera lo que sabe y domina. Siembra y motiva el acercamiento a la ciencia. Guarda el silencio sabio del aire o a la montonera sino a la inteligencia y al corazón individual. El maestro sabe que la educación es obra de la inteligencia y también del corazón, enseña los valores con su ejemplo y actitud. El maestro enseña a pensar como el alumno ha de pensar no a la manera que el maestro piensa, ni pensar lo que piensa el maestro.

En todos los niveles educativos el maestro ama su oficio por sobre su propio haber cognoscitivo y sin proporción, por encima de cuanto gane o devengue en su noble tarea de maestro. Por lo tanto, la esencia del maestro es enseñar a pensar y a ser persona.

Qué clase de docente quiere llegar a ser? Qué clase de docente es $U d$.?

Estas son preguntas que debemos plantearnos en una Universidad donde se enseña una profesión, donde se aplica la informática aplicada y cómo hacer que otros hagan lo que Ud. desea, el dominio de la economía y la vida de los grandes empresarios, la defensa personal y cómo hacerse millonario. Inversamente, en una Universidad donde se enseña una profesión, apreciación informática y artística; la importancia de los valores superiores, la honestidad, el respeto y la solidaridad. El dominio de la voluntad. La cultura Gandhi, la cultura budista: sus enseñanzas, cómo practicar la no violencia y cómo vivir feliz, hacen parte de las características presentadas por cada universidad y que pretenden ser inculcadas a través del currículo. La finalidad es la misma, educarhombresnuevos, perocon diferentesideales y valores que se separan gradualmente por grandes abismos.

En qué tipo de Universidad matricularía a su hijo? Qué clase de Universidad hace Ud. ?

Todo un eje central atraviesa la formación del conocimiento a través de la interdisciplinariedad. Es la conveniente articulación de las ciencias y disciplinas particulares y de los diversos círculos o sectores de afinidad disciplinaria para el estudio de temas complejos con el fin de producir mejores 
e integradas soluciones. Una manera de llegar a determinar cómose refleja la interdisciplinariedad en el currículo de la Universidad es, necesariamente, la cohesión de sus estructuras académicas y administrativas con un acercamiento entre las disciplinas que logran solucionar problemas en forma integral.

Para ello, la interdisciplinaridad se desenvuelve en campos operativos, filosóficos, éticos, sociopolíticos, técnico- médicos y pedagógicos.
Por otro lado, la multidisciplinariedad se define como la yuxtaposición de disciplinas sin ninguna articulación. La pluridisciplinariedad se define como la yuxtaposición de disciplinas con una de ellas como dominante, y finalmente. la transdisciplinariedad, como la superación de la yuxtaposición mediante alguna disciplina articulante con todas las restantes.

El siguiente esquema, muestra cómo la Universidad es estudiada interdisciplinariamente.

\begin{tabular}{|c|c|c|}
\hline & H. & \\
\hline & S & \\
\hline \multirow{3}{*}{ PROSPECTIVA } & R & \multirow{2}{*}{ HISTORIA } \\
\hline & 1 & \\
\hline & & FILOSOFIA \\
\hline \multirow[t]{3}{*}{ ADMINISTRACION } & 1.4 & POLITICA \\
\hline & \multirow{2}{*}{ U. } & DE LA \\
\hline & & EDUCACION \\
\hline
\end{tabular}

El flujo y la aceleración en la producción del conocimiento, generan cambios importantes en la cultura universitaria, dirigiéndose hacia el modernismo en el que los medios electrónicos de comunicación revolucionan la información y por consiguiente inducen la revolución científica. Un ejemplo demuestra que las tres cuartas partes de la información disponible en todo el mundo se ha generado en los últimos veinte años y dicha información se duplica por lo menos cada diez años. Como consecuencia, la ciencia ha tenido que dividir las ciencias y estas en disciplinas cada vez más particulares que estrechan cada vez más los campos de estudio y los abarcan en profundidad pero, desafortunadamente, sin lineas integradoras. La proliferación de disciplinas en lugar de construir una imagen continua y coherente del mundo nos ofrece fragmentos ricos en detalle pero aislados.

Es tal el volumen y la aceleración de la comunicación, que hoy se padece el problema de la sobrecarga de información y ningún tiempo es suficiente ya para seleccionarla, relacionarla y mucho me- 
nos analizarla. El saber que antes un trabajo requería de varias generaciones, se produce hoy en una sola generación. Puede decirse que al terminar el periodo de estudios universitarios, muchos de los conocimientos aprendidos habrán perdido su vigencia y habrán sido sustituídos por otros.

Al igual que lo social, lo político, lo económico, también en la dimensión del conocimiento se debe señalar que lo único permanente es el cambio.

En síntesis, la Universidad y la cultura deben crear una conciencia crítica sobre el conocimiento y sobre la acción social del saber. Estos planteamientos conducen a un nuevo enfoque de la función docente. El docente debe preparar al alumno para el cambio, capacitarlo para que aprenda a aprender. El objetivo debe ser el logro de una persona educable ( $y$ no una persona educada), que pueda adaptarse durante toda la vida al medio ambiente que está en evolución.

El docente debe enseñar a trabajar por la unificación del saber, lo cual debe tener como punto de partida las disciplinas particulares, pero no en sus divergencias sino en su potencial convergente, transdiciplinaria e interdisciplinariamente.

La formación universitaria de la persona debe abarcar además, de lo científico-técnico, los dominios de lo ético, lo estético, lo transcendente. Una formación que conjugue la capacitación profesional orientada a habilidades específicas y una información general, integradora de principios y estructuras capaces de encontrar sentido en medio de una revolución de conocimiento.

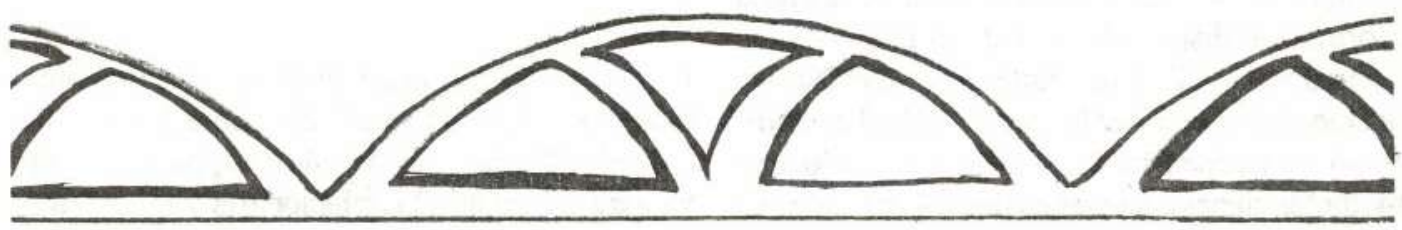

